\title{
Regional Profiles and Precipitation Retrievals and Analysis Using FY-3C MWHTS
}

\author{
Jieying He, Shengwei Zhang \\ Key Laboratory of Microwave Remote Sensing, National Space Science Center, Chinese Academy of Sciences, \\ Beijing, China \\ Email: hejieying@mirslab.cn
}

Received 26 February 2016; accepted 18 April 2016; published 21 April 2016

Copyright (C) 2016 by authors and Scientific Research Publishing Inc.

This work is licensed under the Creative Commons Attribution International License (CC BY). http://creativecommons.org/licenses/by/4.0/

(c) $\underset{\mathrm{EY}}{(1)}$ Open Access

\section{Abstract}

The 89 and $150 \mathrm{GHz}$ channels operated in window are sensitive to precipitation and humidity. The $183 \mathrm{GHz}$ humidity-sensitive channels and $118 \mathrm{GHz}$ temperature-sensitive channels of the Microwave Humidity and Temperature Sounder (MWHTS) on the Chinese Feng Yun 3C MWHTS (FY-3C MWHTS) polar-orbit meteorological satellite responds in part to precipitation. Combining 118 and $183 \mathrm{GHz}$ channels, the paper develops a passive sub-millimeter atmospheric profile and precipitation retrievals algorithm for MWHTS onboard the FY-3C (Feng Yun-3C) satellite. The retrieval algorithm employs a number of back propagation neural network estimators trained and evaluated using the validated global reference physical model NCEP/WRF/ARTS and works for land and seawater with latitude between $\mathbf{- 4 0}$ to 40 degree. NCEP data per 6 hours were downloaded to run the Weather Research and Forecast model WRF, and to derive the typical precipitation data for the whole world. The Atmospheric Radiative Transfer Simulator ARTS is feasible for performing simulations of atmospheric radiative transfer. The results show that the profile retrievals using BP-NN algorithm has the best correlation with those from radiosonde, which is less than $18 \%$ and $1 \mathrm{~K}$ of root mean square error, respectively. For precipitation rate retrievals, a much better agreement is reached with rain gauge and ECMWF datasets, the RMS is between 0.80 to 30.24 $\mathrm{mm} / \mathrm{h}$ for sea surface and 0.789 to $33.11 \mathrm{~mm} / \mathrm{h}$ for land surface according to the classification by precipitation type. Also, the analysis of retrievals located in Tibetan plateau is provided as an example to justify the robustness and performance of retrieving model.

\section{Keywords}

Precipitation, Atmospheric Profile, Microwave Humidity and Temperature Sounder, Tibetan Plateau 


\section{Introduction}

Recently, there are a number of researchers working on retrieving of temperature and humidity profiles and a lot of results have been obtained, which include AMSU-B onboard NOAA-K, L, M satellite with observing frequencies at $89 \mathrm{GHz}, 150 \mathrm{GHz},(183.3 \pm 1) \mathrm{GHz},(183.3 \pm 3) \mathrm{GHz}$ and $(183.3 \pm 7) \mathrm{GHz}$. Several retrieval methods are mainly used to obtain atmospheric temperature and humidity profiles from radiances measured by the microwave instruments. Blackwell used a neural-network technique for retrieving atmospheric temperature and humidity profiles from high spectral resolution sounding data and used neural network for retrieving atmospheric temperature and moisture profiles from cloud-cleared AIRS/AMSU Radiances [1]. Rosencrantz and Susskind retrieved temperature and moisture profiles from AMSU-A and AMSU-B measurements [2] [3]. Boukabara adopted passive microwave remote sensing of extreme weather events using NOAA-18 AMSUA and MHS and used the $183 \mathrm{GHz}$ water vapor line to retrieve clear sky moisture profiles [4]. By using retrieving methods, English Stephen estimated temperature and humidity profile, which are two of the most variable atmospheric constituents and critical elements in the analysis of local weather conditions as well as the validation of global weather conditions [5].

However, retrieval of precipitation profiles is more complex than that of temperature profiles and represents a challenging problem. Passive microwave techniques have long been used to retrieve precipitation over sea using frequencies lower than $100 \mathrm{GHz}$. The longer wavelengths are typically absorbed by precipitation over sea, making it appear warm against the reflective sea, but it is not for precipitation over land, since precipitation generally scatters the shorter wavelengths producing reduced brightness temperatures. In both cases the highly variable brightness temperatures of the precipitation-free background, particularly over land, limit the accuracy of these precipitation estimates [6].

\section{Instrument Description}

FY-3C satellite is China's new generation polar-orbit meteorological satellite, which was successfully launched in Taiyuan launch site in Shanxi province of northern China on Sept 23, 2013 [7]-[9]. Microwave humidity and temperature sounder (MWHTS) onboard FY-3C satellite is a four-frequency, fifteen-channel millimeter wave radiometer, which includes the main sounding channels working at $118.75 \mathrm{GHz}$ for 8 horizontal polarization channels and $183.31 \mathrm{GHz}$ for 5 horizontal polarization channels. Also, it has $89 \mathrm{GHz}$ and $150 \mathrm{GHz}$ (vertical polarization) in atmospheric transparent window, as is shown in Table 1. For the first time, channels working at $118.75 \mathrm{GHz}$ are applied for polar orbiting satellite to improve the temperature and humidity retrieval capabilities of MWHTS, as well as cirrus information in the high troposphere.

MWHTS works in all day and all weather conditions to observe atmospheric humidity and measure the vertical distribution of atmospheric humidity, water vapor and rainfall. It is helpful to implement medium, longterm numerical weather prediction and improve the accuracy of weather forecasts and typhoon monitoring.

Block diagram of reflectors and polarizations for MWHTS is shown in Figure 1.

Figure 2 shows the scanning mode and observing geometry of channels operated at $183 \mathrm{GHz}$ and $150 \mathrm{GHz}$ of MWHTS. For $118 \mathrm{GHz}$ and $89 \mathrm{GHz}$, the angle resolution is $2^{\circ}$. One motor drives two separated reflectors, which enable vertical and horizontal polarization with a polar separated grid respectively. The scanning period is $2.667 \mathrm{~s}$. The main beams of the antenna scan over the observing swath $\left( \pm 53.35^{\circ}\right.$ from nadir) in the cross-track direction at a constant periodicity of $1.71 \mathrm{~s}$. During each period, two-point calibration is performed to calibrate the receiver gain and noise.

\section{Data Collection and Processing}

NCEP datasets per 6 hours from January, 1, 2014 to Aug, 31, 2015 are chosen to run the Weather Research and Forecast model WRF [10] and to derive the typical precipitation data for the whole world, especially for the extreme weather, such as typhoon, cyclone and rainfall. Incomplete cases and latitude values smaller than -40 degree and larger than 40 degree were eliminated. Among the datasets, the cases which satisfy the threshold of precipitation rate larger than $0.1 \mathrm{~mm} / \mathrm{h}$ were valid. The Atmospheric Radiative Transfer Simulator ARTS is used to perform simulations of the atmospheric radiative transfer, and output the brightness temperature values which respect to different angles and surface types.

In a count, 60 typhoon or cyclone cases were extracted for precipitation retrievals training. The whole global 
Table 1. Channel characteristics of MWHTS receivers.

\begin{tabular}{|c|c|c|c|c|c|c|}
\hline No. & $\begin{array}{c}\text { Center } \\
\text { frequency }(\mathrm{GHz})\end{array}$ & Polarization & $\begin{array}{l}\text { Bandwidth } \\
\text { (MHz) }\end{array}$ & $\begin{array}{l}\text { Dynamic } \\
\text { range }(K)\end{array}$ & $\mathrm{NE} \Delta \mathrm{T}(\mathrm{K})$ & $\begin{array}{c}\text { Calibration } \\
\text { accuracy (K) }\end{array}$ \\
\hline 1 & 89.0 & V & 1500 & $3-340$ & 1.0 & 1.3 \\
\hline 2 & $118.75 \pm 0.08$ & $\mathrm{H}$ & 20 & $3-340$ & 3.6 & 2.0 \\
\hline 3 & $118.75 \pm 0.2$ & $\mathrm{H}$ & 100 & $3-340$ & 2.0 & 2.0 \\
\hline 4 & $118.75 \pm 0.3$ & $\mathrm{H}$ & 165 & $3-340$ & 1.6 & 2.0 \\
\hline 5 & $118.75 \pm 0.8$ & $\mathrm{H}$ & 200 & $3-340$ & 1.6 & 2.0 \\
\hline 6 & $118.75 \pm 1.1$ & $\mathrm{H}$ & 200 & $3-340$ & 1.6 & 2.0 \\
\hline 7 & $118.75 \pm 2.5$ & $\mathrm{H}$ & 200 & $3-340$ & 1.6 & 2.0 \\
\hline 8 & $118.75 \pm 3.0$ & $\mathrm{H}$ & 1000 & $3-340$ & 1.0 & 2.0 \\
\hline 9 & $118.75 \pm 5.0$ & $\mathrm{H}$ & 2000 & $3-340$ & 1.0 & 2.0 \\
\hline 10 & 150.0 & V & 1500 & $3-340$ & 1.0 & 1.3 \\
\hline 11 & $183.31 \pm 1$ & $\mathrm{H}$ & 500 & $3-340$ & 1.0 & 1.3 \\
\hline 12 & $183.31 \pm 1.8$ & $\mathrm{H}$ & 700 & $3-340$ & 1.0 & 1.3 \\
\hline 13 & $183.31 \pm 3$ & $\mathrm{H}$ & 1000 & $3-340$ & 1.0 & 1.3 \\
\hline 14 & $183.31 \pm 4.5$ & $\mathrm{H}$ & 2000 & $3-340$ & 1.0 & 1.3 \\
\hline 15 & $183.31 \pm 7$ & $\mathrm{H}$ & 2000 & $3-340$ & 1.0 & 1.3 \\
\hline
\end{tabular}

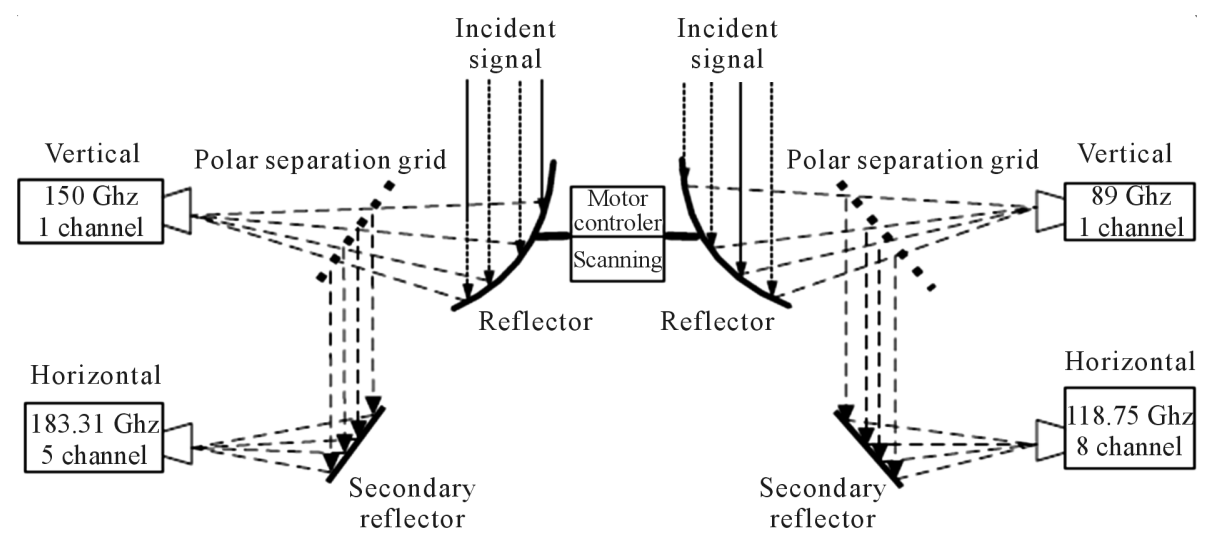

Figure 1. Block diagram of reflectors and polarizations for MWHTS.
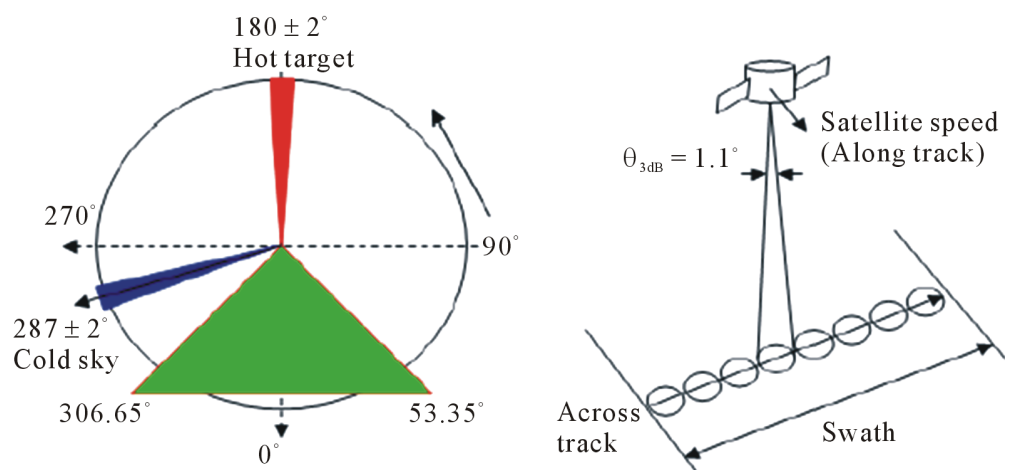

Figure 2. Scanning mode and observing geometry of MWHTS. 
datasets observed by FY-3C MWHTS from January, 1, 2014 to Aug, 31, 2015 were used to evaluate and analyze the validation of retrieval algorithm. The brightness temperature distribution displayed in Figure 3 shows three typhoons happened in Aug, 7th, 2015.

For FY-3C MWHTS, channel 1 (89 GHz) and channel $10(150 \mathrm{GHz})$ and channels operated at near-window frequencies and are sensitive to precipitation. After comparing the $89 \mathrm{GHz}$ and $150 \mathrm{GHz}$, we find that the high frequency channel at $150 \mathrm{GHz}$ allows for a much better discrimination of different types of precipitation than the $89 \mathrm{GHz}$ channel $1.89 \mathrm{GHz}$, which is affected by precipitation. Precipitation can be detected according to the different sensitivities of these two channels. Combined with window channels distributed at $89 \mathrm{GHz}$ and $150 \mathrm{GHz}$, precipitation rate can be retrieved by using neural network estimators.

Data processing steps are as follows:

1) Comparing simulations from NCEP/WRF/ARTS and brightness temperatures observed by FY-3C MWHTS for 3 days (about $2283 \times 8 \times 14$ brightness values/day) - with satellite zenith angle distributed at $0^{\circ}, 5^{\circ}$, $10^{\circ}, 15^{\circ}, 20^{\circ}, 30^{\circ}, 40^{\circ}$ and $50^{\circ}$ Were compared Also, MWHTS brightness temperatures were calibrated against global storms simulated by ARTS.

2) Small brightness temperature biases between NCEP/WRF/ARTS and MWHTS were corrected.

3) Extreme values were omitted.

The following values are omitted: 1) any footprint whose brightness temperature was less than $50 \mathrm{~K}$ or greater than $400 \mathrm{~K}$, which is invalid, 2) the surface altitude that was above $2 \mathrm{~km}$ for |latitude $<40^{\circ}$, which could be covered by snow and are sensed more strongly and were regarded as too-high, or 3 ) values less than $240 \mathrm{~K}$ in channel 1, which implied that the atmosphere was so cold and potentially dry that precipitation was unlikely and that even the most opaque channel such as $183 \pm 1 \mathrm{GHz}$, may sense the surface and yield false detections of precipitation, and was regarded as called too-cold.

\section{Retrieval Algorithm}

\subsection{Rain Detection}

As a polar molecule, water has a very large dielectric constant at microwave frequencies. This property accounts for the high reflectivity (low emissivity) of the ocean surface. The low emissivity of the ocean surface provides a good cold background for viewing particles with relatively higher emissivity, such as rain, over the ocean.

In contrast, land surfaces have emissivity in the range of $0.8-0.95$, and thus the emission algorithms are unsuitable for rainfall-overland because the high surface emissions effectively mask the precipitation attenuation. On the other hand, scattering rainfall algorithms rely on the general cooling in the high-frequency channels due to the scattering by ice in the upper portions of many raining clouds.

Each observation was assigned a probability of 3 classes: precipitation-free, precipitation between 0 and 5 $\mathrm{mm} / \mathrm{h}$, and precipitation higher than $5 \mathrm{~mm} / \mathrm{h}$.

We present a method to remotely sense precipitation and classify its intensity over water, coasts and land surfaces.

Since the method was designed to work over different surface types, it relied mainly on the scattering signal of precipitation sized ice particles received at high frequencies. The high frequency channel at $150 \mathrm{GHz}$ allowed
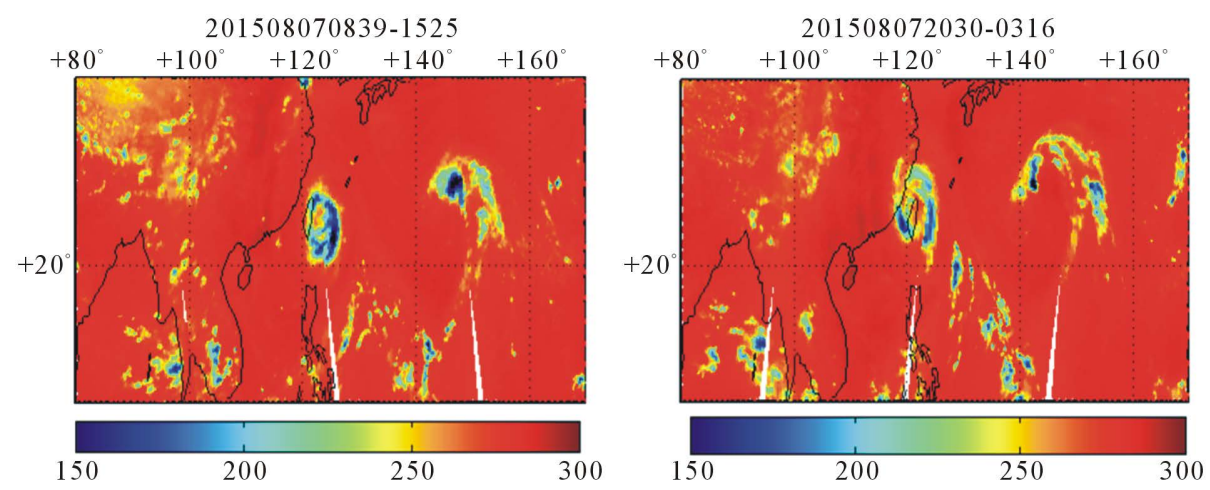

Figure 3. Simulation values of brightness temperature at $183 \pm 1 \mathrm{GHz}$ (2015.8). 
for a much better discrimination of different types of precipitation than the $89 \mathrm{GHz}$ channel. While the precipitation-free areas, as well as heavy precipitating areas $(>5 \mathrm{~mm} / \mathrm{h})$ can be identified to high accuracy, the intermediate classes are more ambiguous [11].

The land/water discrimination was done when using L1 datasets of MWHTS onboard FY-3C The isolation of the scattering signal over land surfaces was simply performed using the difference between a low-frequency channel (89 GHz) and a high frequency channel $(150 \mathrm{GHz})$. For non-precipitating situations, this difference was around zero, whereas for precipitating situations it increased to values higher than $50 \mathrm{~K}$, depending on the total amount of precipitation sized ice in the field of view.

The approach employed here to retrieve precipitation from MWHTS made use of the scattering signature at $150 \mathrm{GHz}$. This enabled us to retrieve precipitation over both sea and land with a spatial resolution of $15 \mathrm{~km}$. The scattering index made use of a predicted brightness temperature $\mathrm{T}$ in the absence of scattering, which was derived from $89 \mathrm{GHz}$ with an offset. The functional relationship between the low frequency brightness temperature and $T_{-}$can either be found by inverse radiative transfer modeling, or by global brightness temperature statistics. A nonlinear regression method for s was used empirically to determine the coefficients for all precipitation observations against the local zenith angle. Then a threshold of $\mathrm{S}$ can be defined as whether it is precipitation free. According to this, the equation can be derived as follows.

For land surface

For over land surfaces, the following algorithm was employed. It depends on MWHTS footprint and considered land surface as homogeneous land.

$$
\mathrm{sl} 1=(\mathrm{T} 89-\mathrm{T} 150)-(0.1483+0.01638 \theta+0.0021 \theta 2)
$$

where $\theta$, given in degrees, is the zenith angle of the observation. The last term corrects for the weak dependence of the difference of the brightness temperatures on zenith angle. We found it empirically by regressing for all precipitation-free observations against the local zenith angle.

For Sea surface

$$
\mathrm{ss} 1=(\mathrm{T} 89-\mathrm{T} 150)-(-39.1310+0.1131 \theta+0.0005 \theta 2)
$$

where $\theta$, given in degrees, is the zenith angle of the observation. The last term corrects for the dependence of the difference of the brightness temperatures on zenith angle. There was a considerable offset between T89 and T150 over water and it was also corrected. This correction is probably the least general part of the set of algorithms since it is supposed to be strongly dependent on the water vapor path and atmospheric temperature and thus may not be valid for other regions with completely different atmospheric conditions. It can, however, easily be generalized by adjusting the offset to the observed mean difference between T89 and T150 for a given area.

For Coasts surface

The algorithm we use for coasts is a mixture of the land (Equation (1)) and sea (Equation (2)) algorithms:

$$
\mathrm{sc}=(1-\mathrm{L}) \mathrm{ss} 1+\mathrm{Lsl} 1
$$

where $\mathrm{L}$ is the fraction of land in the MWHTS footprint, ss1 is the scattering index derived from Equation (2) and sl1 is the scattering index derived from Equation (1). The weighted average according to the fraction of land in the footprint also automatically weights the zenith angle and offset corrections for the land and sea parts. Thus, regardless of the fraction of land in the footprint, a precipitation-free scene has an average scattering index of 0 K.

\subsection{Profile and Precipitation Retrieving}

To retrieve precipitation rate for FY-3C MWHTS, neural networks was employed to realize training and evaluating for sea and land, respectively [12]. As section 3 described, 60 typhoon or cyclone cases were simulated by the validated global reference physical model, NCEP/WRF/ARTS, which is composed of the U.S National Center for Environment Prediction (NCEP) analyses, the new generation National Center for Atmospheric Research/Penn State Mesoscale Model (WRF) and the Atmospheric Radiative Transfer Simulator, ARTS, which is a software for performing simulations of atmospheric radiative transfer (Figure 4).

For temperature retrievals, the neural network model consists of three layers, including nine neurons for input layer, 14 neurons for hidden layer and 58 neurons for output layer. For humidity retrievals, the neural network 


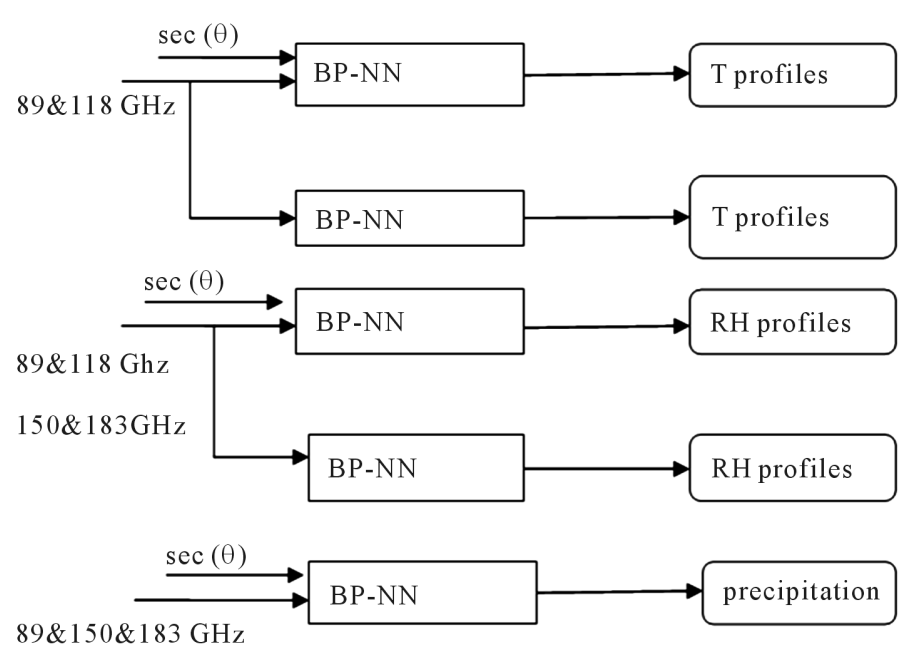

Figure 4. Schematic of retrieving flow.

model consists of three layers, including 15 neurons for input layer, 18 neurons for hidden layer and 58 neurons for output layer. while, for precipitation retrievals, the neural network model consists of three layers, including 7 neurons for input layer, 10 neurons for hidden layer and 1 neuron for output layer.

Here, we have dataset with a period of Jan, 2014 to Aug, 2015. The profile data were randomly divided into three no overlapping sets that we shall term the training set (80\%), the validation set (10\%), and the testing set $(10 \%)$. The selection of profiles for the data sets was identical for all performance comparisons. The training set was used to derive the network weights and biases. The network training was stopped if the error on the validation set did not decrease after ten consecutive training epochs or if 500 epochs were reached. Each NN was trained ten separate times with random initializations, and the validation set was used to select the best of the ten networks. All the NN retrieval results presented in this paper were derived using the testing set.

For ocean, the results showed that BP-NN can be in common used according to the classification of tropic, mid-latitude and polar region. But for land, the situation was more complex. so we got detection results according to the scattering information and instructed many BP-NN models according to latitude classification and the landmark, which was provided by level1 data of MWHTS. When operating the retrieving procedure, a satisfied BP-NN model was chosen and continued the following steps.

\section{Retrieval Results and Analysis}

Combining channels near $118.75 \mathrm{GHz}, 183.31 \mathrm{GHz}, 89 \mathrm{GHz}$ and $150 \mathrm{GHz}$, the authors constructed a back propagation neural network for retrieving atmospheric temperature and humidity profiles simultaneously and quickly. The retrievals were consistent with radiosonde observing data. Figure 5 to Figure 6 showed atmospheric humidity profiles and temperature profiles using neural network algorithm, including comparison and root mean square (RMS) error between radiosonde and retrievals from ANN mode.

For the temperature profile, when there was a thin inversion layer, large deviations occurred from the neural network retrieval model. It was mainly because of its own shortcoming for nonlinear neural network. When the inversion layer was thick enough, the neural network inverse model can be well reflected for the details of atmospheric temperature changes. Water vapor varied significantly from time to time and from space to space, the amount of water vapor in the air varied from practically zero to about 4 percent by volume. Certainly the fact was that water vapor was the source of all clouds and precipitation which would be enough to explain its retrieving difficulties. Therefore compared to temperature, water vapor and relative humidity profiles were retrieved with relatively larger difficulty with challenge. The retrievals showed that the RMS of atmospheric temperature profile was less than $2.5 \mathrm{~K}$, RMS of atmospheric relative humidity profile was $17.7 \%$, which can be converted to atmospheric absolute humidity, and the RMS was less than $0.35 \mathrm{~g} / \mathrm{m}^{3}$ as shown in Figure 4 to Figure 5. The new generation MWHTS can derive more accurate retrievals of atmospheric humidity profile, the RMS reduced to about $17.7 \%$ and $0.35 \mathrm{~g} / \mathrm{m}^{3}$, compared to AMSU-B onboard NOAA series [13] and MWHS onboard FY-3A/B series [14]-[17]. 


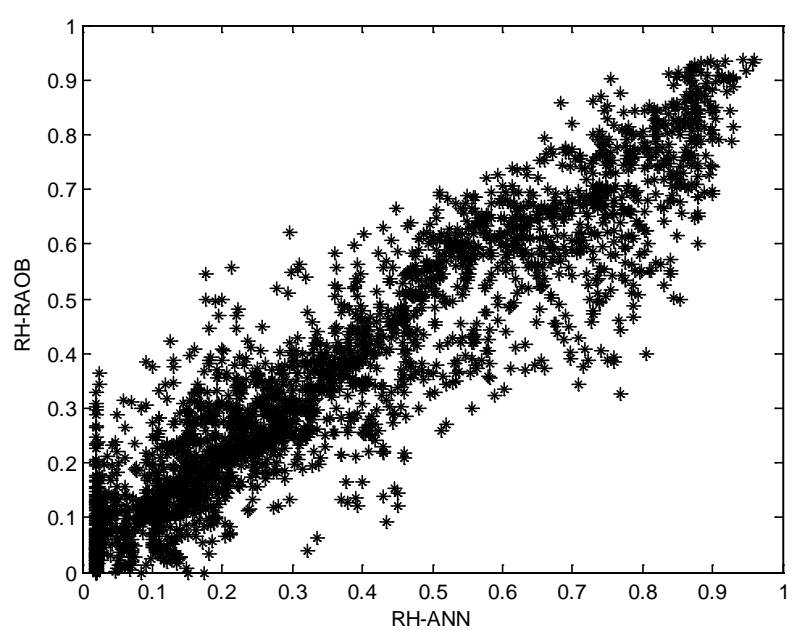

(a)

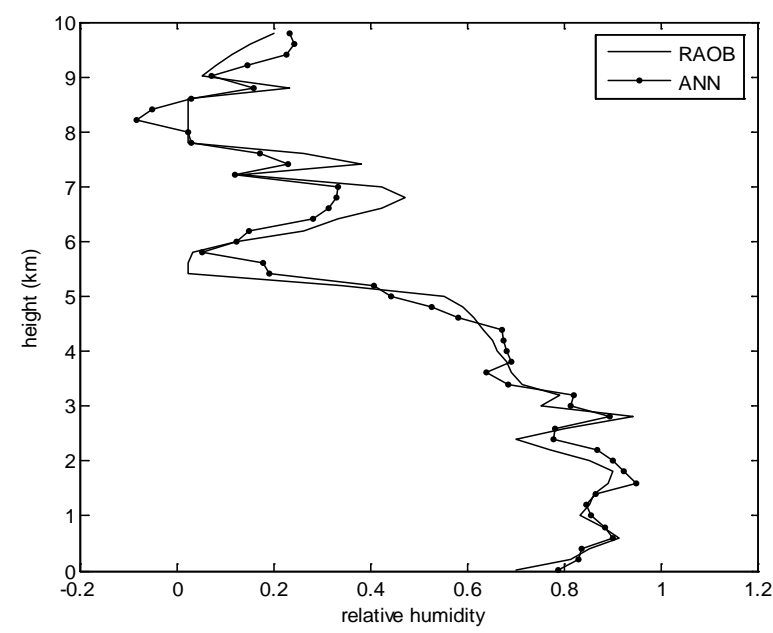

(b)

Figure 5. Atmospheric humidity profiles retrievaled from new generation MWHTS. (a) Relationships of relative humidity profiles from ANN retrievals and radiosonde; (b) One example of relative humidity profile comparison between from ANN retrievals and radiosonde.

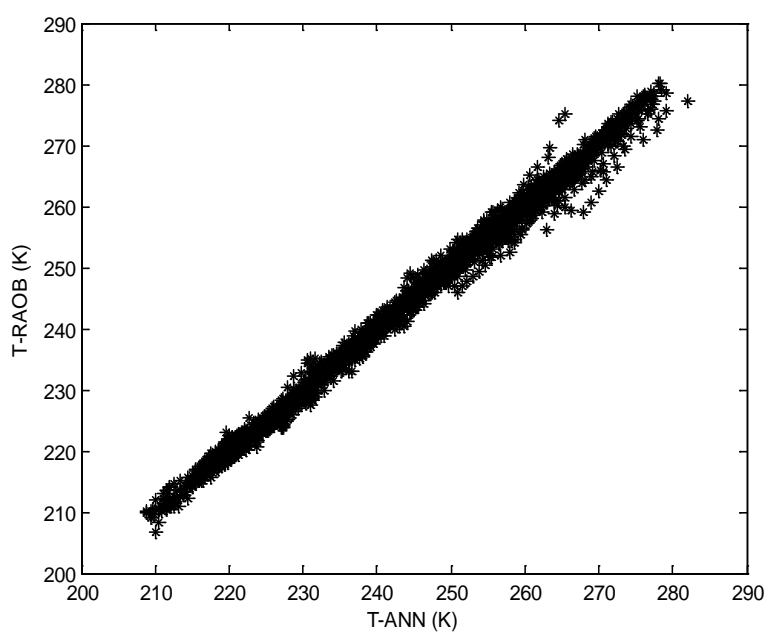

(a)

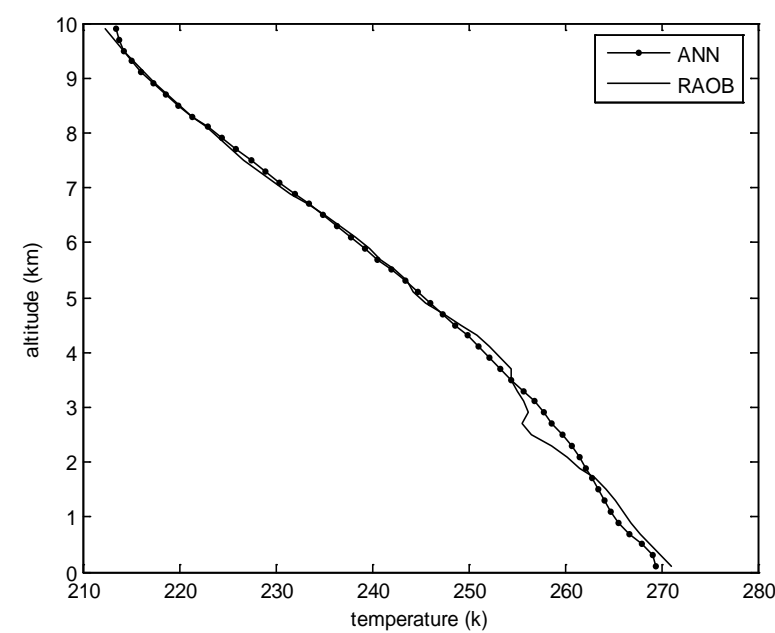

(b)

Figure 6. Atmospheric temperature profiles retrieved from new generation MWHTS. (a) Relationships of temperature profiles from ANN retrievals and radiosonde; (b) One example of temperature profile comparison between from ANN retrievals and radiosonde.

For precipitation, the primary radiometric signal at frequencies around $183 \mathrm{GHz}$ from precipitating scenes resulted from the scattering by ice hydrometeors [18]. This scattering can result in significant brightness temperature depressions (several 10's K) relative to non-precipitating surroundings, and was therefore a sensitive proxy for the presence of precipitation at the surface.

According to the global difference distributions of brightness temperatures on Jan 20, 2015, (a) channel 10 plus channel 15, (b) for channel 10 plus channel 9, and (c) for channel 9 plus channel 15 for FY-3C MWHTS, using neural network method, the precipitation and rain detection can be derived, which were shown in Table 2.

Compared with rain gauge measurements and rain products from global data reanalysis, the correlation coefficient can be denoted as:

$$
\mathrm{R}=\frac{\mathrm{n} \sum \mathrm{xy}-\sum \mathrm{x} \sum \mathrm{y}}{\sqrt{\mathrm{n} \sum \mathrm{x}^{2}-\left(\sum \mathrm{x}\right)^{2} \sqrt{\mathrm{n} \sum \mathrm{y}^{2}-\left(\sum \mathrm{y}\right)^{2}}}}
$$


Table 2. Rain detection of typhoon domain by FY-3C MWHTS between Jan, 1 to Oct, 31, 2014.

\begin{tabular}{cccc}
\hline Location & Rain Rate $(\mathrm{mm} / \mathrm{h})$ & Sea rms/K & Land rms/K \\
\hline $0.1-1$ & 0.79 & 0.80 \\
Typhoon domain & $1-5$ & 4.01 & 3.52 \\
& $5-10$ & 7.26 & 6.45 \\
& $10-30$ & 20.03 & 16.21 \\
& $30-50$ & 21.22 & 20.43 \\
& $50-65$ & 33.11 & 30.24 \\
\hline
\end{tabular}

where, $\mathrm{R}=0$ means no relationship, $0<|\mathrm{R}|<0.2$ means lowest-correlation, $0.2<|\mathrm{R}|<0.4$ means low-correlation, $0.4<|\mathrm{R}|<0.7$ means common-correlation, $0.7<|\mathrm{R}|<0.9$ means high-correlation, $0.9<|\mathrm{R}|<1$ means high-correlation.

In this paper, the correlation coefficient was affected by precipitation values. The correlation coefficient was0.818 in this study, which means there was strong correlation. Certainly, more data are still needed to get better conclusions.

The precipitating algorithm gives the likelihood of precipitation in five intensity classes:

C0: No precipitation $<0.1 \mathrm{~mm} / \mathrm{h}$

C1: Very light precipitation $0.1 \sim 1 \mathrm{~mm} / \mathrm{h}$

C2: Light to moderate Precipitation $1 \sim 5 \mathrm{~mm}=\mathrm{h}$

C3: Heavy precipitation $5 \sim 10 \mathrm{~mm} / \mathrm{h}$

C: Heavy precipitation $>\mathrm{mm} / \mathrm{h}$

The likelihood in all five classes had to sum up to $100 \%$. The total likelihood of precipitation was the sum of the likelihood in classes one to three. Since all information was already contained in classes one to three, no output was given for class0, which thus can be calculated by 100\%-total precipitation likelihood.

The confusion matrix for the precipitation detection is shown in Table 3.

Daily accumulated precipitation was categorized and the contingency table represents the empirical joint distributions of retrievals and observations. This contingency table was subsequently constructed into $2 \times 2$ contingency tables (Table 4), to analyze how well the models were able to retrieve precipitation greater.

As a measure quantifying the skill of a forecast the Equitable Threat Score (ETS) was used:

$$
\mathrm{ETS}=\frac{(\mathrm{A} 1-\mathrm{C})(\mathrm{A} 1+\mathrm{B} 1+\mathrm{A} 2-\mathrm{C})}{\mathrm{N}}
$$

where, $\mathrm{C}$ is the number of hits by chance, and can be denoted as:

$$
\mathrm{C}=\frac{(\mathrm{A} 1+\mathrm{B} 1)(\mathrm{A} 1+\mathrm{A} 2)}{\mathrm{N}}
$$

With $\mathrm{N}=\mathrm{A} 1+\mathrm{A} 2+\mathrm{B} 1+\mathrm{B} 2$ being the total number of observations. The ETS with the value of 0.42 emphasizes correct “yes”-events (hits), while correct negatives (B2, see Table 4) were not considered.

\section{Take Qianghai-Tibetplateau for Instance}

Qinghai-Tibet Plateau is an area sensitive to global climate change, which located in China's western region (25 40 degrees north latitude, longitude 75 - 105 degrees). In recent years, although the research of surface soil temperature and moisture has been extensively developed, since the weather stations are scarce and lack of observational data, the uncertainty of temperature and humidity profiles is large and needed to be improved. Precipitation analysis is also important for Qinghai-Tibetan plateau, because it is located in high altitude and far from the ocean.

Furthermore, this paper focused on research and analysis of atmospheric profiles located on Qinghai-Tibet plateau. Combined the in-orbiting observation of Microwave humidity and temperature sounder (MWHTS) 
Table 3. Confusion matrix for the precipitation detection.

\begin{tabular}{|c|c|c|c|c|c|c|c|c|c|c|c|c|}
\hline \multirow{3}{*}{ Surface } & \multicolumn{12}{|c|}{$89 \mathrm{GHz} \& 150 \mathrm{GHz}$} \\
\hline & \multicolumn{4}{|c|}{ Land } & \multicolumn{4}{|c|}{ Sea } & \multicolumn{4}{|c|}{ Coastal } \\
\hline & $\mathrm{C} 1$ & $\mathrm{C} 2$ & C3 & C4 & $\mathrm{C} 1$ & $\mathrm{C} 2$ & C3 & $\mathrm{C} 4$ & $\mathrm{C} 1$ & $\mathrm{C} 2$ & C3 & $\mathrm{C} 4$ \\
\hline $\mathrm{C} 1$ & 48.6 & 34.2 & 16.1 & 1.1 & 82.4 & 16.68 & 0.79 & 0.13 & 68.5 & 26.4 & 3.8 & 1.3 \\
\hline $\mathrm{C} 2$ & 27.8 & 46.2 & 21.1 & 4.9 & 11.7 & 56.0 & 30.5 & 1.8 & 21.8 & 40.6 & 29.3 & 8.3 \\
\hline C3 & 12.9 & 14.3 & 43.5 & 29.3 & 5.3 & 28.3 & 50.2 & 16.2 & 6.2 & 31.2 & 48.5 & 14.1 \\
\hline C4 & 0.84 & 2.1 & 12.3 & 84.76 & 1.1 & 6.9 & 31.2 & 60.8 & 2.1 & 8.1 & 23.7 & 66.1 \\
\hline
\end{tabular}

Table 4 . A $2 \times 2$ contingency table of precipitation.

\begin{tabular}{cccc}
\hline & & Observed & \\
\cline { 2 - 4 } & & Yes & No \\
\hline Retrieved & Yes & A1 & B1 \\
& No & B2 & A2 \\
\hline
\end{tabular}

Where, A1: hits, B1: false alarms, B2: misses, A2: correct negatives.

onboard FY-3C satellite (FY-3C), this study analyzed the seasonal variation and distribution of temperature and humidity in Qinghai-Tibet plateau.

Figure 7 showed the brightness temperature distribution for water vapor-sensitive channels on JAN, 20th, 2015.

According to the characteristics of all channels, temperature and humidity profiles can be derived using back propagation neural network algorithm, as shown in Figure 8. Left column showed relationships of temperature and humidity profiles from ANN retrievals and radiosonde, right column showed one example of temperature and humidity profile comparison between ANN retrievals and radiosonde. Figure 9 and Figure 10 showed temperature and humidity profile distribution of 10 days average for Tibetan plateau from April, 2014 to March, 2015.

\section{Summary and Conclusions}

MWHTS plays an important role in studying global climate and it is the main remote sensing instrument for meteorology and disaster. It works in all weather and all day conditions and provides the observation of brightness temperature which can be used to retrieve temperature and humidity profiles and precipitation rate.

There was a strong correlation of temperature and humidity profiles between radiosonde and retrievals. Compared to radiosonde, retrievals showed that the RMS of atmospheric temperature profile was less than $1 \mathrm{~K}$, RMS of atmospheric relative humidity profile was less than $18 \%$, which can be converted to atmospheric absolute humidity, and the RMS was less than $0.35 \mathrm{~g} / \mathrm{m}^{3}$. Also, this paper provides a confusion matrix and ETS analysis for the precipitation detection. Since Tibetan plateau provides a large temperature variation but very poor humidity and precipitation contrasts over seasons, therefore, this paper occupies a section to analyze the retrievals in Tibet.

For the recent work, the surface mark was classified as land, sea and coastal. The work of using the observing data to detect whether it was rain or not has been carried out and then the accuracy of the precipitation rate was tested and validated. Therefore, the study provides algorithms and data analysis of temperature and humidity profiles and precipitation retrievals. The study will play an important role in the design and development of following meteorological satellites.

Further improvement has to be done such as considering the surface covered by snow, ice and rainforest. Also, according to convection and stratiform, in order to retrieve the rain rate, different precipitation rate from 0 to 50 needs to be classified as detail as possible. The radar data are also needed to validate the accuracy of rain detection. All of above will be described in future paper. 

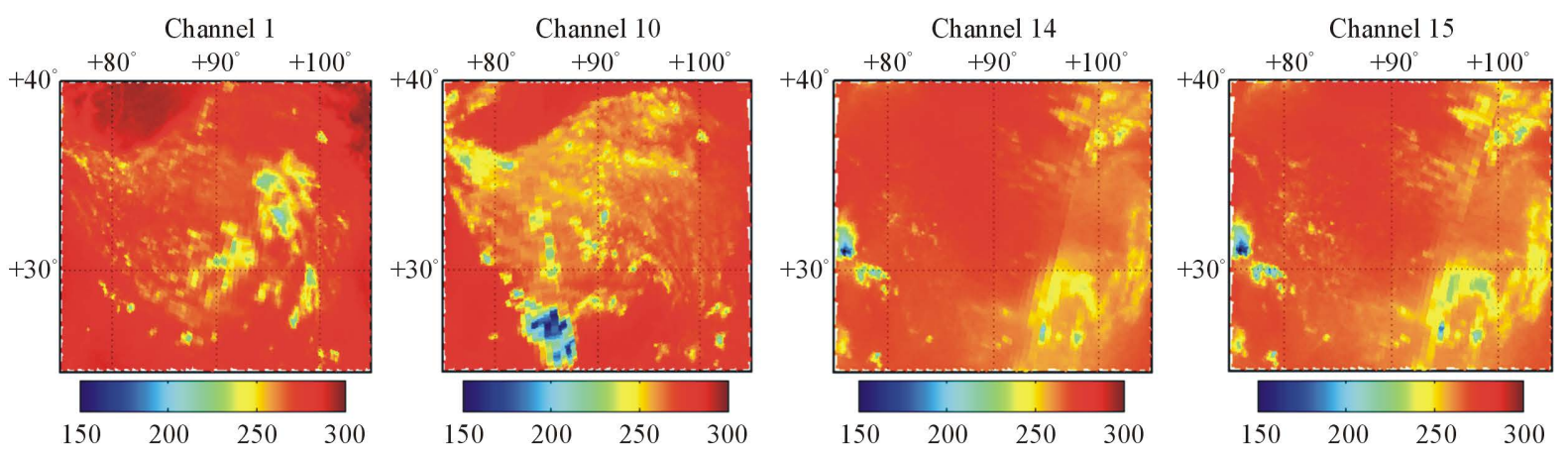

Figure 7. Brightness temperature distribution for water vapor-sensitive channels on Jan, 20th, 2015.
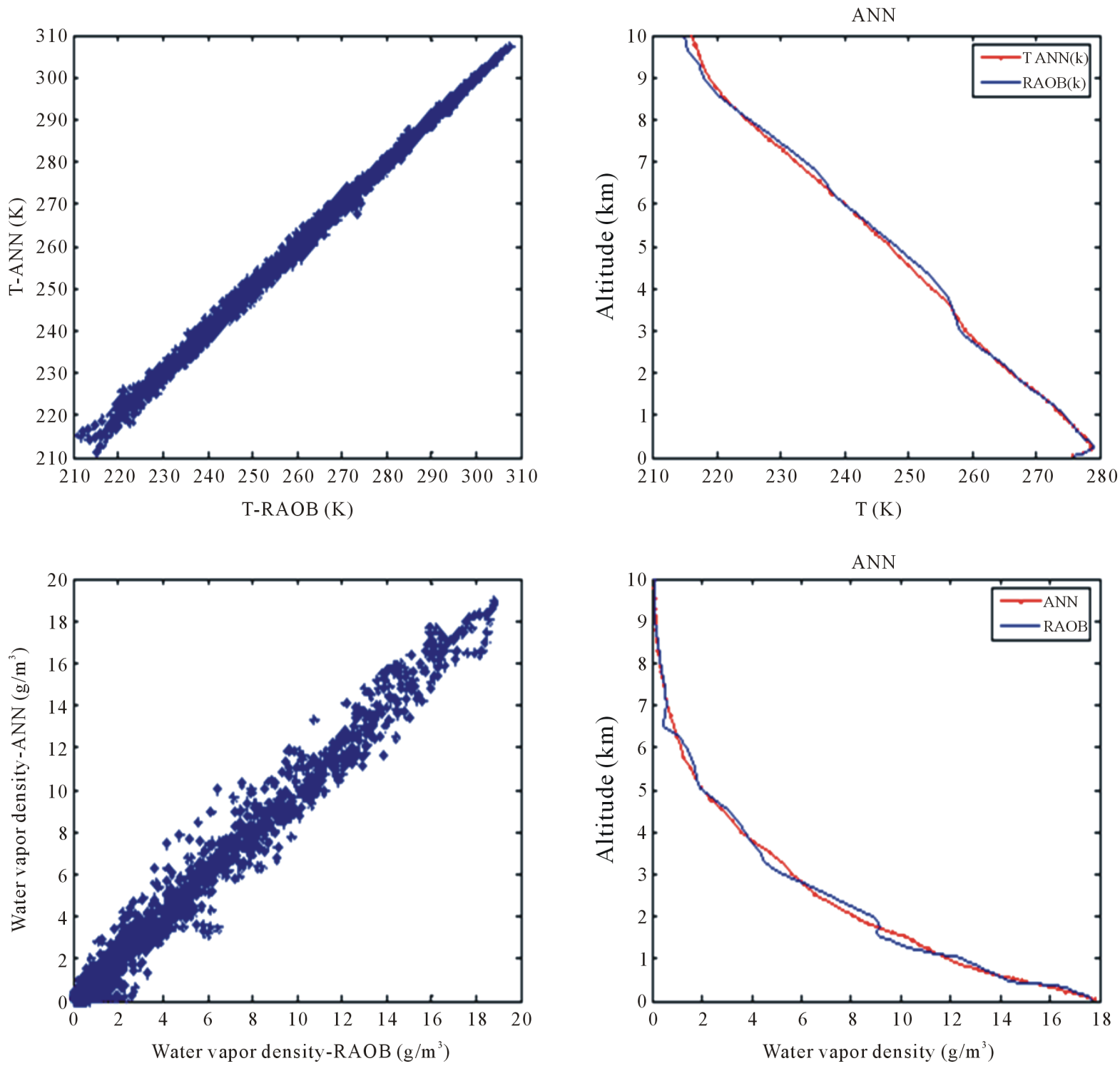

Figure 8. Atmospheric temperature profiles retrievals from new generation MWHTS. (Up-left) Relationships of temperature profiles from ANN retrievals and radiosonde; (Up-right) One example of temperature profile comparison between from ANN retrievals and radiosonde; (Down-left) Relationships of humidity profiles from ANN retrievals and radiosonde; (Down-right) One example of humidity profile comparison between from ANN retrievals and radiosonde. 


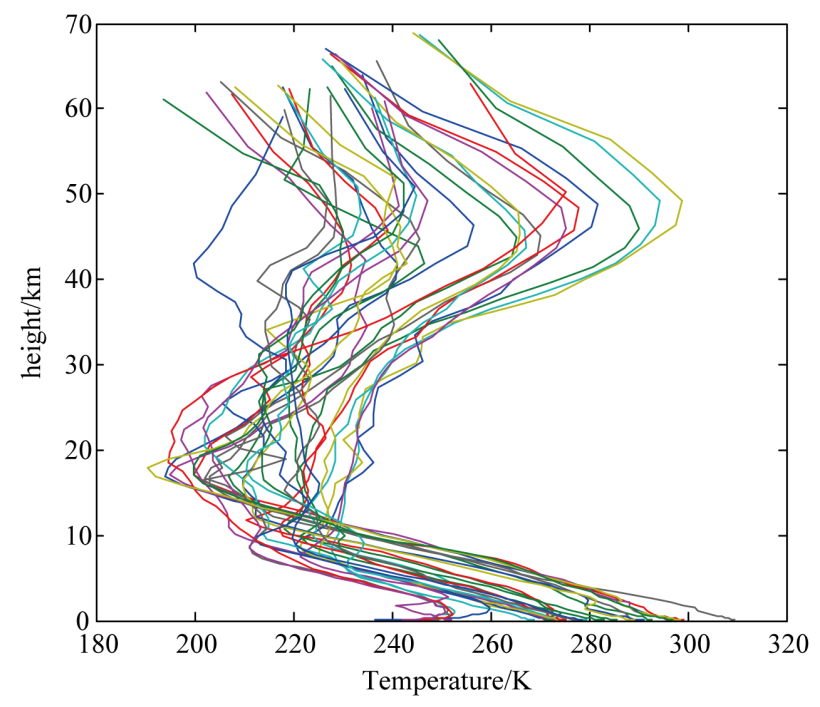

Figure 9. Temperature profile distribution of 10 days average for Tibetan plateau from April, 2014 to March, 2015.

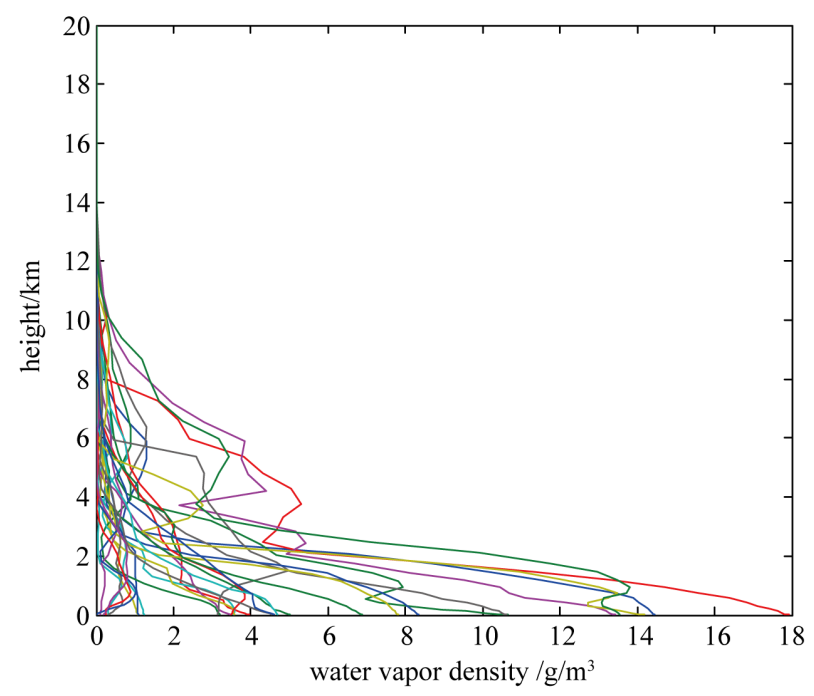

Figure 10. Humidity profile distribution of 10 days average for Tibetan plateau from April, 2014 to March, 2015.

\section{Acknowledgements}

The authors are so grateful to C. Surussavadee for all his help, and wish to thank the Pennsylvania State University and the University Corporation for Atmospheric Research for providing us with WRF and technical support and the National Center for Atmospheric Research for assistance with NCEP global troposphere analyses.

\section{References}

[1] Blackwell, W.J. (2004) Neural Network Retrieval of Atmospheric Temperature and Moisture Profiles from CloudCleared AIRS/AMSU Radiances. IEEE International Geoscience and Remote Sensing Symposium (IGARSS), 3, 20662069.

[2] Rosenkranz, P.W. (2003) Rapid Radiative Transfer Model for AMSU/HSB Channels. IEEE Transactions on Geoscience and Remote Sensing, 41, 362-368. http://dx.doi.org/10.1109/TGRS.2002.808323

[3] Susskind, J., Barnet, C.D. and Blaisdell, J.M. (2003) Retrieval of Atmospheric and Surface Parameters from AIRS/ AMSU/HSB Data in the Presence of Clouds. IEEE Transactions on Geoscience and Remote Sensing, 41, 390-409. 
http://dx.doi.org/10.1109/TGRS.2002.808236

[4] Boukabara, S.A., Weng, F.Z. and Liu, Q.H. (2007) Passive Microwave Remote Sensing of Extreme Weather Events Using NOAA-18 AMSUA and MHS. IEEE Transactions on Geoscience and Remote Sensing, 45, 2228-2246. http://dx.doi.org/10.1109/TGRS.2007.898263

[5] English, S.J. (2003) Atmospheric Temperature Analysis Using Microwave Radiometry. Remote Sensing of Atmosphere and Ocean from Space: Models, Instruments and Techniques, 13, 67-78. http://dx.doi.org/10.1007/0-306-48150-2_5

[6] Surussavadee, C. and Staelin, D.H. (2006) Comparison of AMSU Millimeter-Wave Satellite Observations, MM5/ TBSCAT Predicted Radiances, and Electromagnetic Models for Hydrometeors. IEEE Transactions on Geoscience and Remote Sensing, 44, 2667-2678. http://dx.doi.org/10.1109/TGRS.2006.873275

[7] Dong, C., Yang, J., Lu, N., et al. (2009) An Overview of a New Chinese Weather Satellite FY-3A. Bulletin of the American Meteorological Society, 90, 1531-1544. http://dx.doi.org/10.1175/2009BAMS2798.1

[8] Zhang, S.W., Li, J., Jiang, J., Zhang, Y., Wang, Z. and Dong, X. (2006) Microwave Humidity Sounder (MWHS) of Chinese Meteorological Satellite FY-3. Proceedings of the Microwave Technology and Techniques WorkshopEnabling Future Space Systems, ESA/ESTEC, Noordwijk, 15-16 May 2006, ESA SP-632.

[9] Zhang, S.W., Li, J. and Wang, Z.Z. (2012) Design of the Second Generation Microwave Humidity Sounder (MWHS-II) for Chinese Meteorological Satellite FY-3. IEEE International Geosciences and Remote Sensing Symposium (IGARSS), 22-27 July 2012, Munich, 4672-4675.

[10] Chen, S.H. and Dudhia, J. (2005) Annual Report: WRF PHYSICS [R/OL]. http://www2.mmm.ucar.edu/wrf/users/docs/wrf-doc-physics.pdf

[11] Bennartz, R. and Thoss, A. (2002) Precipitation Analysis Using the Advanced Microwave Sounding Unit in Support of Nowcasting Applications. Meteorological Applications, 9, 177-189. http://dx.doi.org/10.1017/S1350482702002037

[12] He, J.Y., Zhang, S.W. and Wang, Z.Z. () The Retrievals and Analysis of Water Vapor Density in Arctic Regions Using FY-3A Satellite MWHS, Radio Science.

[13] He, J.Y., Zhang, S.W., et al. (2011) The Primary Design of Advanced Ground-Based Atmospheric Microwave Sounder and Retrieval of Physical Parameters. Journal of Quantitative Spectroscopy \& Radiative Transfer, 2, .

[14] Karbou, F., Aires, F., Prigent, C., et al. (2005) Potential of Advanced Microwave Sounding Unit-A (AMSU-A) and AMSU-B Measurements for Atmospheric Temperature and Humidity Profiling over Land. Journal of Geophysical Research, 110, D07109. http://dx.doi.org/10.1029/2004JD005318

[15] Sahoo, S., Bosch-Lluis, X., Reising, S.C. and Vivekanandan, J. (2015) Radiometric Information Content for Water Vapor and Temperature Profiling in Clear Skies Between 10 and $200 \mathrm{GHz}$. IEEE Journal of Selected Topics in Applied Earth Observations and Remote Sensing, 8, 859-871.

[16] Sahoo, S., Bosch-Lluis, X., Reising, S. and Vivekanandan, J. (2015) Optimization of Background Information and Layer Thickness for Improved Accuracy of Water-Vapor Profile Retrieval from Ground-Based Microwave Radiometer Measurements at K-Band. IEEE Journal of Selected Topics in Applied Earth Observations and Remote Sensing, 8, 4284-4295. http://dx.doi.org/10.1109/JSTARS.2014.2370073

[17] Blackwell, W.J. and Milstein, A.B. (2014) A Neural Network Retrieval Technique for High-Resolution Profiling of Cloudy Atmospheres. IEEE Journal of Selected Topics in Applied Earth Observations and Remote Sensing, 7, 1260-1270.

[18] Surussavadee, C. (2006) Passive Millimeter-Wave Retrieval of Global Precipitation Utilizing Satellites and a Numerical Weather Prediction Model. Ph.D. Dissertation, MIT, Cambridge, MA. 